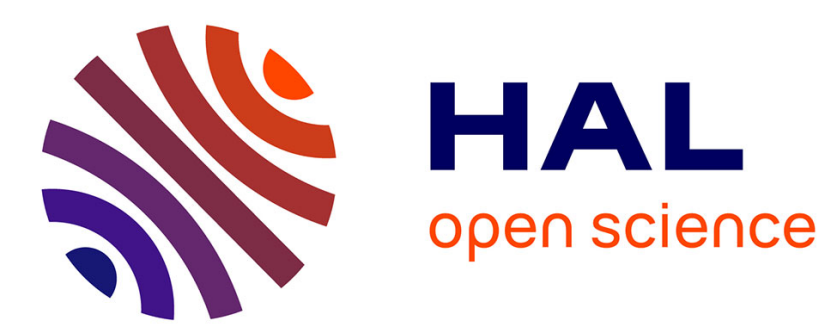

\title{
An ephemeral Frenkel pair in iridium
}

\author{
M.-H. Gély, A. Dunlop, Y. Quéré
}

\section{To cite this version:}

M.-H. Gély, A. Dunlop, Y. Quéré. An ephemeral Frenkel pair in iridium. Journal de Physique Lettres, 1983, 44 (6), pp.219-224. 10.1051/jphyslet:01983004406021900 . jpa-00232183

\section{HAL Id: jpa-00232183 https://hal.science/jpa-00232183}

Submitted on 1 Jan 1983

HAL is a multi-disciplinary open access archive for the deposit and dissemination of scientific research documents, whether they are published or not. The documents may come from teaching and research institutions in France or abroad, or from public or private research centers.
L'archive ouverte pluridisciplinaire HAL, est destinée au dépôt et à la diffusion de documents scientifiques de niveau recherche, publiés ou non, émanant des établissements d'enseignement et de recherche français ou étrangers, des laboratoires publics ou privés. 


\title{
LE JOURNAL DE PHYSIQUE-LETTRES
}

J. Physique - LETTRES 44 (1983) L-219 - L- 224

15 MARS 1983, PAGE L-219

Classification

Physics Abstracts

$23.00-61.80$

\section{An ephemeral Frenkel pair in iridium $\left({ }^{*}\right)$}

\author{
M.-H. Gély, A. Dunlop and Y. Quéré \\ Section d'Etude des Solides Irradiés, C.E.N., B.P. 6, 92260 Fontenay-aux-Roses, France
}

(Reçu le 9 novembre 1982, accepté le 28 janvier 1983)

\begin{abstract}
Résumé. - Après activation sous flux de neutrons, de l'iridium est maintenu à basse température $(22 \mathrm{~K})$. La résistivité électrique décroît ou croît au cours du temps suivant que l'activation a été faible ou forte. Une interprétation cohérente est donnée qui implique la création, par recul radioactif, d'une paire de Frenkel durant l'activation, et son annihilation ultérieure (avec une probabilité égale à $\simeq 0,8$ ) par un second recul sous seuil.

Abstract. - After neutron activation, iridium samples have been kept at low temperature $(22 \mathrm{~K})$. The electrical resistivity decreases or increases with time according to whether the activation was moderate or high. A coherent interpretation is given implying the recoil-induced creation of a Frenkel pair during activation and its subsequent annihilation, with a probability $\simeq 0.8$, due to a second subthreshold recoil.
\end{abstract}

During a reactor neutron irradiation of a solid, one is usually interested in the effects due to the elastic collisions of the neutrons with the nuclei : production of isolated or more or less agglomerated point defects, of dislocation loops, of disorder... We describe here another effect due to the inelastic collisions of the thermal neutrons with the nuclei; it consists in a sequence of two contradictory events : first the creation of a Frenkel pair due to a radioactive recoil of energy higher than the threshold displacement energy, then a rigourously athermal recombination of this same pair due to another subthreshold recoil.

1. Experiment and results. - For the experiment iridium is irradiated at a low temperature $T_{0}$ in a nuclear reactor. After the irradiation the electrical resistivity $\rho$ of the metal was measured at the temperature $T_{0}$ as a function of time $t$.

We use an iridium wire $(150 \mu \mathrm{m}$ diameter $)$ of nominal purity $99.9 \%$. It has been recrystallised in a good vacuum $\left(5 \times 10^{-8}\right.$ torr $)$ at $1300{ }^{\circ} \mathrm{C}$ (sample heated by Joule effect). Its resistivity ratio $\rho_{300} / \rho_{4}$ is $34 \pm 1$. The irradiation facility is the VINKA system located in the TRITON reactor of Fontenay-aux-Roses. This facility [1,2] allows us to maintain the samples at constant tempera-

(*) La version française de cet article a été proposée aux Comptes Rendus de l'Académie des Sciences. 
tures around $20 \mathrm{~K}$ (temperature stability : $0.02 \mathrm{~K}$ ), the samples being in or out of the neutron flux. The temperature and the electrical resistivity (sensitivity : 10-4) are measured [3].

Two experiments (named (I) and (II) in the following) have been successively pertormed on two different samples. They mainly differ by the fluences of the initial irradiation and by the time during which the measurements out of the flux have been made later. The characteristics of the two experiments are quoted in the table, in which a distinction is made between the thermal $(\simeq 1 / 40 \mathrm{eV})$ and the fast $(\gtrsim 1 \mathrm{MeV})$ neutrons:

Table. - Characteristic numbers describing the two experiments.

\begin{tabular}{|c|c|c|c|c|}
\hline & $\begin{array}{l}\text { Flue } \\
\text { fast neutrons }\end{array}$ & $\begin{array}{l}\text { n. } \mathrm{cm}^{-2} \text { ) } \\
\text { thermal neutrons }\end{array}$ & $\begin{array}{c}\Delta \rho_{0} \\
(\mu \Omega . \mathrm{cm})\end{array}$ & $\begin{array}{l}\text { Duration of the } \\
\text { out of flux } \\
\text { measurements } \\
\text { (days) }\end{array}$ \\
\hline $\begin{array}{l}\text { Experiment (I) } \\
\text { Experiment (II) }\end{array}$ & $\begin{array}{l}4.08 \times 10^{18} \\
3.63 \times 10^{17}\end{array}$ & $\begin{array}{l}5.02 \times 10^{18} \\
4.47 \times 10^{17}\end{array}$ & $\begin{array}{l}2 \\
0.16\end{array}$ & $\begin{array}{l}9.8 \\
2\end{array}$ \\
\hline
\end{tabular}

One should note from this table that the fluence is approximately 10 times greater for (I) than for (II).

Our results can be summarized as follows :

1) in both experiments the resistivity increases during the irradiation, which is a usual phenomenon due to the accumulation of defects. We shall not comment further on this point. The resistivity increase $\Delta \rho_{0}$ at the end of the irradiation is, as is the fluence, about 10 times greater for (I) than for (II);

2) then, out of the flux, at a constant temperature $\left(T_{0}=22 \mathrm{~K}\right)$, the resistivity $\rho$ changes as a function of time : $\rho$ increases for (I) and decreases for (II) (see the $\Delta \rho_{\text {exp. }}(t)$ curves on Fig. 1).

We shall discuss and interpret this result 2) and the apparent contradiction.

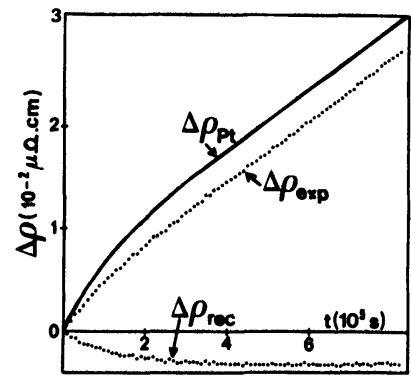

a)

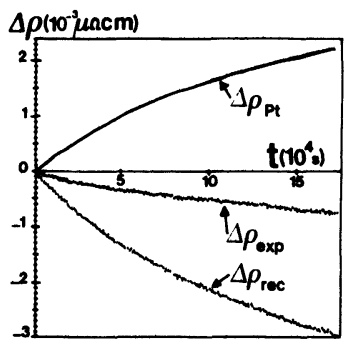

b)

Fig. 1. - Iridium samples have been initially irradiated with reactor neutrons. Their resistivity is then measured at $22 \mathrm{~K}$ out of the neutron flux as a function of time during two experiments noted (I) (Fig. $a$ ) and (II) (Fig. $b$ ) :

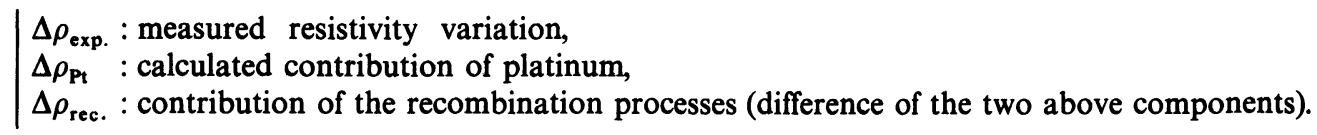

2. Interpretation. - 2.1 PRODUCTION OF PLATINUM. - Iridium consists of $38.5 \%{ }^{191} \mathrm{Ir}$ and $61.5 \%{ }^{193} \mathrm{Ir}$. In the presence of slow (and especially thermal) neutrons it undergoes a series of nuclear reactions which are described on figure 2 . 


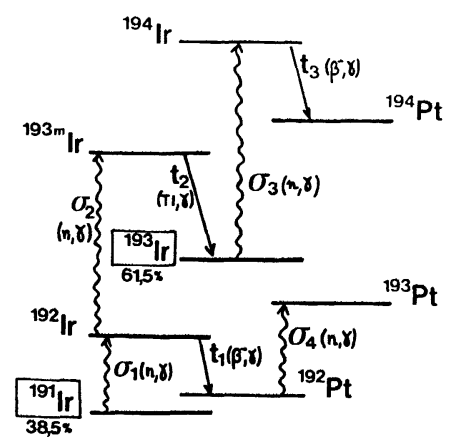

Fig. 2. - Activation diagram of iridium :

$$
\begin{aligned}
& \sigma_{1}=1000 \text { barns, } \quad \sigma_{2}=700 \text { barns, } \quad \sigma_{3}=130 \text { barns, } \quad \sigma_{4}=90 \text { barns. } \\
& t_{1}=74 \text { days, } \quad t_{2}=12 \text { days, } \quad t_{3} \simeq 20 \mathrm{hrs} \text {. }
\end{aligned}
$$

We see immediately that these reactions lead to the creation of platinum, either during or after the irradiation. The various periods and cross-sections being known (see [4]), one can easily calculate the atomic concentration of platinum which is created as a function of time : $c_{\mathrm{Pt}}(t)$. This can be done either during the irradiation or during the isothermal measurements after irradiation. The concentration of platinum is small (for example $c_{\mathrm{Pt}} \simeq 4.7 \times 10^{-4}$ at. at the beginning of the isotherm following irradiation (I)) but is easy to reveal through resistivity measurements. In a separate experiment, once the point defects had been thermally annihilated [4], we have let that platinum accumulate during a long period ( 6 months) and could thus determine precisely the value of the specific resistivity of substitutional platinum in iridium :

$$
\Delta \rho_{\mathrm{Pt}}=(160 \pm 20) c_{\mathrm{Pt}} \quad(\mu \Omega . \mathrm{cm}) .
$$

Using this number and the calculated $c_{\mathrm{Pt}}(t)$, one can then determine how platinum contributes $\left(\Delta \rho_{\mathrm{P}_{\mathrm{t}}}(t)\right)$ to the isotherms measured out of the neutron flux. This contribution is quoted on figures $1 a$ and $1 b$ as well as the measured $\Delta \rho_{\text {exp. }}(t)$.

2.2 ReCOMBINATIONŚ. - One sees immediately from figure 1 that the creation of platinum accounts poorly (Exp. I) or quite badly (Exp. II) for the measured $\Delta \rho_{\text {exp. }}(t)$. In both cases, $\Delta \rho_{\text {exp. }}$ is smaller than $\Delta \rho_{\mathrm{Pt}}$. The complementary,contribution $\Delta \rho_{\text {rec. }}$, such that $\left(\Delta \rho_{\text {rec. }}+\Delta \rho_{\mathrm{Pt}}\right)$ is equal to the measured $\Delta \rho_{\text {exp. }}$, can be deduced as $\Delta \rho_{\text {rec. }}=\Delta \rho_{\text {exp. }}-\Delta \rho_{\mathrm{Pr}}$. It is negative and is shown on figures $1 a$ and $1 b$.

Taking into account the various species "existing in the samples : point defects (and especially isolated Frenkel pairs) and platinum atoms, we postulate that this resistivity decrease $\Delta \rho_{\text {rec. }}$ can only be attributed to a recombination of Frenkel pairs, this recombination being induced by one of the nuclear reactions. Such recombinations have been previously observed by Coltman et al. [10].

What is known of Frenkel pairs in iridium has been determined through $4 \mathrm{~K}$ electron irradiations. It can be summarized as follows :

i) the threshold for atomic displacement is $T_{\mathrm{d}}=(46 \pm 2) \mathrm{eV}$ [5];

ii) the resistivity of a concentration $c$ of Frenkel pairs is $(670 \pm 50) c \mu \Omega . \mathrm{cm}[5]$;

iii) there is rigorously no thermal recombination of an interstitial and a vacancy below a temperature of $35 \mathrm{~K}$ [5]. 
Let us now consider the evolution of $\Delta \rho_{\mathrm{rec} .}$. It varies exponentially as :

$$
\Delta \rho_{\text {rec. }}(t)=-\Delta \rho_{\infty}\left[1-\exp -\left(\frac{t}{\tau} \ln 2\right)\right]
$$

with the following quantities :

a) the half life $\tau$ is equal to $23 \mathrm{hrs}$ for (I) and (II);

b) the saturation resistivity $\Delta \rho_{\infty}$ is equal to $3.2 \times 10^{-3} \mu \Omega$.cm for (I) and to $3.7 \times 10^{-3} \mu \Omega$.cm for (II).

Point $a$ ) is strongly in favour of a same mechanism for recombination in (I) and (II).

Point $b$ ) is more striking : the total resistivity $\Delta \rho_{\infty}$ of the defects which are likely to recombine is of the same order for both experiments in which however the fluences differ by a factor of $\simeq 10$. We are thus naturally inclined to see if, among all the different isotopes created during the irradiation, there is one which would attain its quasi-equilibrium sufficiently rapidly so as to exist with similar concentrations at the end of (I) and at the end of (II). The calculation of the concentrations (see [4]) shows that it occurs for ${ }^{194} \mathrm{Ir}$ : at the end of irradiations (I) and (II) one finds respectively $c_{4}^{(\mathrm{I})}=3.4 \times 10^{-5}$ and $c_{4}^{(\mathrm{II})}=1.4 \times 10^{-5}$ for ${ }^{194}$ Ir. Moreover the half life $t_{3}$ of this isotope (see Fig. 2) is known with poor accuracy $\left(17.4<t_{3}<20.7 \mathrm{hrs}\right.$ [6 to 8]), but is close to the period of (1) (see $a$ ) above).

2.3 MeChANiSM OF CREATION-RECOMBINATION. - We are now naturally led to the following scheme :

The isotope ${ }^{194} \mathrm{Ir}$ is created by activation during the irradiation through the reaction ${ }^{193} \operatorname{Ir} \stackrel{(n, \gamma)}{\longrightarrow}{ }^{194} \mathrm{Ir}$. The iridium activation $\gamma$ spectrum is shown on figure 3 . From this spectrum and taking into account [11] the fact that $\gamma$ rays are emitted in cascades, one can evaluate the number of Frenkel pairs created by efficient recoils (i.e. of energy higher than the threshold energy

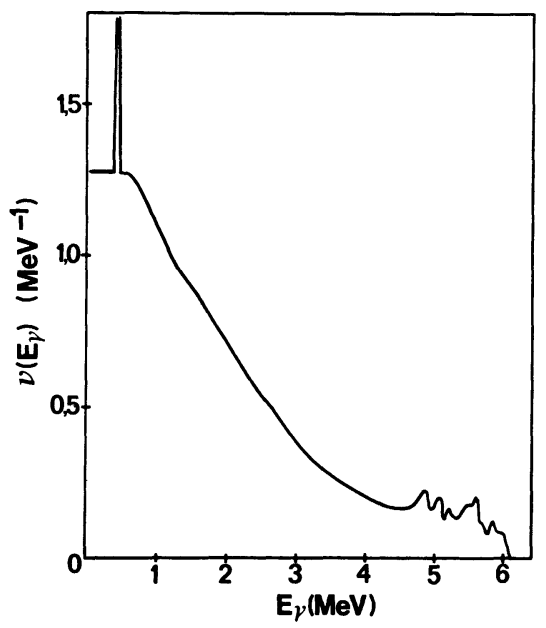

Fig. 3. $-\gamma$ spectrum following the capture of thermal neutrons by iridium, established from [9]. For details about determination of Frenkel pair creation by recoils, see [12].

$T_{\mathrm{d}}=46 \mathrm{eV}$ from i) above). From this evaluation we conclude that when $100{ }^{194} \mathrm{Ir}$ nuclei are formed, 55 Frenkel pairs are simultaneously created. Each of these Frenkel pairs, named below $(l-i)_{4}$, consists of a vacancy $(l)$ located near the ${ }^{194}$ Ir atom and of an interstitial $(i)$ located outside the recombination volume $V$ of the vacancy (Fig. 4). Let us recall here that the creation of point 


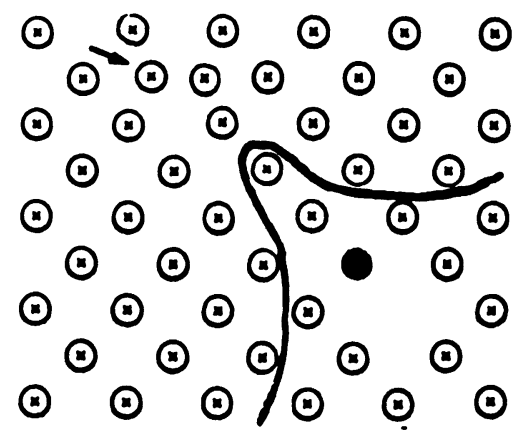

Fig. 4. - Configuration of the ephemeral $(l-i)_{4}$ Frenkel pair in iridium. The activation ${ }^{193} \mathrm{Ir} \rightarrow{ }^{194} \mathrm{Ir}$ has produced a vacancy at the initial position of the ${ }^{193} \mathrm{Ir}$ atom, which has been displaced to a neighbouring lattice site (black circle is ${ }^{194} \mathrm{Ir}$ atom). A split interstitial (see arrow) has been produced out of the recombination volume $V$ (continuous line) of the vacancy. The subsequent disintegration of the ${ }^{194} \mathrm{Ir}$ atom annihilates this Frenkel pair.

defects through recoil phenomena has been observed in quite a few metals [10]. At the end of the irradiation, we are thus left with a concentration $c_{4}^{\prime j}=0.55 c_{4}^{j}$ of $(l-i)_{4}$ pairs, where $c_{4}^{j}$ is the concentration of ${ }^{194}$ Ir atoms $(j=$ (I) or (II)).

During the subsequent out of flux measurements, the temperature is held constant $\left(T_{0}=22 \mathrm{~K}\right)$, so that these interstitials will not undergo any thermal recombination (see iii) above). On the other hand ${ }^{194} \mathrm{Ir}$ transforms into ${ }^{194} \mathrm{Pt}$ with a half-life $t_{3}$ (see Fig. 2). The average recoil energy $(\approx 18 \mathrm{eV})$ is now inferior to the threshold energy. This energy, dissipated in the volume $V$, is too small to create a new Frenkel pair but can be sufficient to allow the recombination of the $(l-i)_{4}$ pair. This ability to induce the above recombination depends on the exact recoil energy $E_{4}$ and on the direction of the impulse of the recoil. When averaged over all the possible events it defines a recombination probability $p . c_{4}^{\prime}$ changes then according to :

$$
c_{4}^{\prime}(t)=c_{4}^{\prime j}-p \cdot c_{4}^{\prime j}\left[1-\exp -\left(\frac{t}{t_{3}} \ln 2\right)\right],
$$

which corresponds to a recombination resistivity :

$$
\Delta \rho_{\text {rec. }}(\mu \Omega . \mathrm{cm})=-670 p\left(0.55 c_{4}^{j}\right)\left[1-\exp -\left(\frac{t}{t_{3}} \ln 2\right)\right] \text {. }
$$

This evolution is that which we found experimentally (1), the half-life $\tau=23 \mathrm{hrs}$ being close to $t_{3}(\simeq 20 \mathrm{hrs})$. The knowledge of $\Delta \rho_{\infty}$ in (1) and that of $c_{4}^{\prime j}$ in (2) (see $\left.\S 2.2\right)$ leads to the experimentally measured probabilities :

$$
p=0.26 \text { for (I) and } p=0.73 \text { for (II). }
$$

The periods agree fairly well, especially when one keeps in mind that the radioactive half-lives, particularly $t_{3}$, are known with bad accuracy. The two experimental values for $p$ differ noticeably $\left({ }^{1}\right)$.

$\left({ }^{1}\right)$ Let us remark here that the above mechanism could also be considered when ${ }^{192} \mathrm{Ir}$ disintegrates (see Fig. 2). This isotope is indeed created in much larger quantities than ${ }^{194} \operatorname{Ir}\left(c_{2}^{(\mathrm{I})}=1.8 \times 10^{-3}\right.$ and $c_{2}^{\text {(II) }}=1.7 \times 10^{-4}$ at the end of irradiations (I) and (II) respectively). ${ }^{192}$ Ir has a larger radioactive half-life (74 days) than ${ }^{194} \operatorname{Ir}(\simeq 20 \mathrm{hrs})$. Moreover the corresponding average recoil is only $\approx 3 \mathrm{eV}$ which is much smaller than that of ${ }^{194} \operatorname{Ir}(\simeq 18 \mathrm{eV})$. The above results prove that when the recoil is of only $\approx 3 \mathrm{eV}$, the corresponding recombination probability $p$ is negligible.

The recoil energy $(\simeq 0.02 \mathrm{eV})$ corresponding to the ${ }^{193 \mathrm{~m}} \mathrm{Ir} \rightarrow{ }^{193} \mathrm{Ir}$ reaction, is thus certainly not sufficient to induce any recombination. 
2. 4 COMMENT UPON THE RECOMBINATION PROBABILITY $p$. - The experimental value of $p$ is higher for the short (II) than for the long irradiation (I). These differences in irradiation fluence imply that defect recombination under irradiation is much higher at the end of (I) than at the end of (II). At the end of (I) the production rate $\Delta \rho(=\mathrm{d} \Delta \rho / \mathrm{d} t)$ is but 0.45 times its initial value. A great number of the $(l-i)_{4}$ pairs which were formed no longer exist at the end of this irradiation and thus cannot participate in the recombinations described in $\S 2$.3. This leads to an underestimation of $p$. The correction is much smaller at the end of irradiation (II) for which the production rate is still 0.83 times its initial value.

The true value of $p$, noted $p_{0}$, is that which would correspond to an ideally short irradiation. When we linearly extrapolate the experimental values to zero resistivity increase we obtain :

$$
p_{0}=0.8 \pm 0.1
$$

3. Conclusion. - We have shown here that the irradiation of iridium by slow neutrons creates an ephemeral Frenkel pair, which is created during the activation ${ }^{193} \mathrm{Ir} \rightarrow{ }^{194} \mathrm{Ir}$ and destroyed later (with a probability $p_{0}$ ) by subthreshold events occuring when ${ }^{194} \mathrm{Ir}$ transforms into ${ }^{194} \mathrm{Pt}$. After these two successive events we end up with a substitutional atom of ${ }^{194} \mathrm{Pt}$ in a perfect lattice.

When the mean recoil energy is $18 \mathrm{eV}$, the recombination probability $p_{0}$ is equal to 0.8 .

Acknowlegments. - We thank very sincerely D. Lesueur for interesting and helpful discussions. The French version of this paper has been submitted to "Comptes Rendus de l'Académie des Sciences ".

\section{References}

[1] Conte, R. R., Adv. Cryog. Eng. 12 (1967) 673.

[2] S.E.S.I., J. Mat. Nucl. 108, 109 (1982) 152.

[3] Bouffard, S., Rapport C.E.A.-R-5015 (1979).

[4] Gely, M. H., C.E.A.-N, in print (1982).

[5] Dunlop, A., Gely, M. H. (to be published in Radiat. Eff.).

[6] Pannetier, R., Vade-mecum du technicien (imprimerie Maisonneuve) 1966.

[7] Lederer, C. M., Hollander, J. M., Perlman, I., Table of isotopes (John Wiley ed.) 1978.

[8] Seren, L., Friedlander, H. N., Turkel, S. H., Phys. Rev. 72 (1947) 888.

[9] Groshev, L. V., Demidov, A. M., LutSenko, V. N., Pelekhov, V. I., Atlas of $\gamma$-ray Spectra from Radiative Capture of Thermal Neutrons (Pergamon Press-New York) 1959.

[10] Coltman, R. R., Klabunde, C. E., Redman, J. K., Southern, A. L., Rad. Eff. 16 (1972) 25.

[11] WalkeR, R. M., J. Nucl. Mater. 2 (1960) 147.

[12] Gely, M. H., Note CEA (1983), in press. 